\title{
Automation for the Artisanal Economy: Enhancing the Economic and Environmental Sustainability of Crafting Professions with Human-Machine Collaboration
}

\section{Accepted Aug 8, 2019 to Al \& Society}

Corresponding author:

Ron Eglash (eglash@umich.edu), Professor, School of Information, University of Michigan, 4389 North Quad, 105 S. State St., Ann Arbor, Ml 48109-1285. ORCID\# 0000-0003-1354-1300

Co-authors:

Lionel Robert (Iprobert@umich.edu); Associate Professor, UM School of Information. ORCID\# 0000-0002-1410-2601

Audrey Bennett, (agbennett@umich.edu), Professor, UM School of Art and Design. ORCID\# 0000-0002-6763-2622

Kwame Porter Robinson (kwamepr@umich.edu), Graduate Student, UM School of Information. ORCID\#0000-0003-2663-571X

Michael Lachney (lachneym@msu.edu), Assistant Professor, Michigan State University, Department of Counseling, Educational Psychology and Special Education. ORCID\# 00000003-3310-8707

William Babbitt (babbiw2@rpi.edu), Research Associate, Rensselaer, Department of Science and Technology Studies. ORCID\# 0000-0002-2684-4901

\begin{abstract}
Artificial intelligence (Al) is poised to eliminate millions of jobs, from finance to truck driving. But artisanal products-(e.g. handmade textiles) are valued precisely because of their human origins, and thus have some inherent "immunity" from Al job loss. At the same time, artisanal labor, combined with technology, could potentially help to democratize the economy, allowing independent, small scale businesses to flourish. Could Al, robotics and related automation technologies enhance the economic viability and environmental sustainability of these beloved crafting professions, perhaps even expanding their niche to replace some job loss in other sectors? In this paper we compare the problems created by the current mass production economy, and potential solutions from an artisanal economy. In doing so, the paper details the possibilities of utilizing Al to support hybrid forms of human-machine production at the microscale; localized and sustainable value chains at the meso-scale; and networks of these localized and sustainable producers at the macro scale. In short, a wide range of automation technologies are potentially available for facilitating and empowering an artisanal economy. Ultimately, it is our hope that this paper will facilitate a discussion on a future vision for more "generative" economic forms in which labor value, ecological value and social value can circulate without extraction or alienation.
\end{abstract}

Keywords: human-machine collaboration; artisanal economy; generative justice; industrial symbiosis; ethnocomputing 
Acknowledgement: The authors would like to acknowledge National Science Foundation grants DRL-1640014 and DGE-0947980 in support of this work. 


\section{Introduction}

\subsection{Overview}

Artificial intelligence $(\mathrm{Al})$ is poised to eliminate millions of jobs, from finance to truck driving. But artisanal products-handmade textiles, furnishings, adornments, foods, and so on-are valued precisely because of their human origins, and thus have some inherent "immunity" from Al job loss. Just as importantly, while many of the jobs AI can (and should) replace are dull or dangerous, artisanal labor is at the other end of the spectrum:- one of the most satisfying occupations possible (Luckman 2015; Sennett 2008). Artisanal labor, combined with technology, could potentially help to democratize the economy, allowing independent, small scale businesses to flourish (Diez and Posada 2013). Finally, many artisans strive to be more environmentally sustainable, using "green" supply chains and techniques (Marsden and Smith 2005; Cimatti et al 2017). Could Al, robotics and related automation technologies enhance the economic viability and environmental sustainability of these beloved crafting professions, perhaps even expanding their niche to replace some job loss in other sectors?

Part 2 of this paper will compare the problems created by the current mass production economy, and potential solutions from an artisanal economy. We show that mass production problems may be exacerbated by automation, and that these are generally problems of extraction. The problems can be generally classified as the extraction of labor value from workers; the extraction of ecological value from nature; and the extraction of social value from civic activity. We then review the potential for solutions in an artisanal economy: replacing extraction with a generative network in which value circulates in unalienated forms. Hence the need for new forms of automation that can scale up these generative alternatives.

Parts 3, 4, and 5 of this paper details the possibilities of automation technologies for facilitating and empowering an artisanal economy at three scales:

Part 3: At the economic micro-scale, we examine how human-machine collaboration can sustain and empower the kinds of "unalienated" (enjoyable, meaningful) labor tasks that make artisanal jobs attractive. In particular, our findings show distinctly different outcomes from that of Gombolay et al (2015). In their scenario, workers preferred to cede task control to automated machines, which modelled context of mass production. Our initial experiments with humanmachine collaborations situated in African American, African, and Native American artisanal traditions (Eglash et al. forthcoming; Lachney et al. forthcoming) show distinctly different preferences depending on the context.

Part 4: At the meso-scale, we examine how automation technologies--in particular Albased pattern recognition--could be used to help consumers authenticate product origins and producers improve fabrication sustainability.

Part 5: Finally, at the macro-scale, we provide a brief review of the ways that natural language processing, network optimization algorithms and related technologies might be deployed to develop a robust technosocial ecosystem for the artisanal economy as a whole. 
In the conclusion of this paper, we will summarize the above analysis, and provide some directions forward. It is our hope that this research will move discussions beyond the exclusive focus on "green tech" often occurring in literature on "circular economies" or "industrial symbiosis". We propose that Al could play a transformative role towards futures in which unalienated labor value, unalienated ecological value, and unalienated social value circulate in mutually supporting networks; what we have defined elsewhere (Eglash 2015) as generative justice.

\section{Problems in the mass production economy; potential solutions in the artisanal economy}

\subsection{Labor, environmental, and social problems in mass production.}

The term "alienation" is used in two senses here. The psychological interpretation-estrangement, meaninglessness, and so on--is often appropriate to describing symptoms of worker dissatisfaction in mass production. But Marx (1844) used the phrase "alienation of labor value" to describe the cause: something that properly belongs to the workers has been taken ("alienated") from them. In his view artisans can "see themselves" in their craft; and take pride in the social relations developed in learning, creating and distributing. Since labor value alienation has been just as damaging in mass production under state-owned factories as private industry (Burawoy 1985), Marx's hope that the remedy could be simply a matter of removing capitalism seems unlikely ${ }^{1}$. Hence many seek solutions in technological innovation, as we will describe through the example of human-machine collaboration.

Recent literature on human-machine work collaboration has frequently focused on collaborative robots ("cobots"), where humans and robots work together side by side to accomplish shared work goals (Colgate et al. 1996; Peshkin and Colgate 1999; You et al. 2018). Human-robot work collaboration is being offered as a potential solution to the fear of massive job losses due to automation. But, as we detail below, our preliminary research shows two different faces to this work. As an example of public-facing discourse, Rethink Robotics has produced TED talks and other media showing how "cobots" allow workers to continue in a new collaborative role. But in their industry-facing discourse, CEO Scott Eckert's blog (Eckert 2016) explicitly positions cobots as solving "the rising cost of labor", implying massive layoffs. Indeed robots are expected to replace nearly half the human workforce in 10-20 years (Ackerman. 2014, Owais et al. 2014; Webster, 2014). In many cases robots will entirely replace their human counterparts. For example, robotic process automation (RPA) provides "digital workers" which can both perform the work of humans and manage other "digital workers." (Lacity \& Willcocks, 2016; Le Clair, 2017).

Even aside from the threat of large scale job displacement, the marriage of human and robotic labor is not without its own challenges. Of key concern for our research is that the vast majority of these studies offer no alternative to a future of mass production. It is critical that "Future of Work" studies include alternatives to mass production for the following reasons:

a. Mass production work has alienated labor value; turning what should be an enjoyable aspect of life into tasks that are monotonous, that limit worker control over process, and that fail to offer

\footnotetext{
${ }^{1}$ Wendling (2009) summarizes Marx's view as follows: "Capitalist production marks a necessary transitional phase and is itself productive of the material wealth that will bring about its dissolution. After this dissolution, workers need not to smash but to own machines, for in doing so they reclaim the accumulated wealth of their class."
} 
a sense of pride in the fruits of our activity. Often summarized as a lack of "job decision latitude" these features are correlated with mental strain (Karasek 1979), cardiovascular disease (Karasek et al 1981); work-related depression (Michelsen and Bildt, 2003); suicide (Woo and Postolache 2011), and other maladies.

b. Mass production manufacturing has alienated ecological value, resulting in devastating environmental impacts. Direct effects include about 8 million metric tons of plastic entering the ocean annually (expected to increase to 80 million by 2025); land, water and air dispersal of heavy metals; pesticides; cleaning agents; organochlorides; VOCs and other toxins (Kannan 1991; Jambeck et al 2015; Coccia 2017). Indirect effects include global warming; ocean acidification; and mass extinction (Vallero 2015; de Souza Machado, 2016; Dirzo et al 2014).

c. Mass production economies have alienated social value. If production no longer provides meaning, then consumption begins to take up more and more of our social value and identity. A whole industry is thus formed around convincing people to buy things they don't need: this includes adware, spyware, social media marketing, "click bait", and so on. The discipline of "neuro-marketing" attempts to fine-tune these tools with brain science; potentially overcoming sensible restraint in ways that some consider unethical (Nadler 2014). Adverse psychological effects include a "hedonic treadmill" in which purchases only increase buying aspirations (Chancellor and Lyubomirsky 2011); the loneliness and depression linked to adware-funded and driven social media platforms (Hunt et al 2018); increased focus onto extrinsic rather than intrinsic goals (Kasser and Ryan 1996); and a decrease in academic achievement for consumption-obsessed youth (Bunce et al 2017). Further social alienation includes the use of "product placement" for toys and fast food in children's media, tying over-consumption of unhealthy foods with the cognitive damage of excessive screen time (Story and French 2004). Advocates of mass production may criticize the concept of an artisanal economy because they maintain that it is incapable of generating the massive streams of consumer goods we currently produce: indeed, one can only hope it does not.

\subsection{The potential of artisanal economies}

All three domains--labor alienation, ecological alienation, and social alienation--can be addressed in terms of artisanal economies. The phrase "artisanal economy" was first introduced by historians and rural sociologists to describe pre-industrial forms of production, but it increasingly appears as a vision of the future in which small scale entrepreneurs network to create custom-made products. Harvard labor economist Lawrence Katz has tied this vision to automation impacts: "It's possible that information technology and robots eliminate traditional jobs and make possible a new artisanal economy ... an economy geared around selfexpression, where people would do artistic things with their time" (Thompson 2015).

While Katz stresses the fit between an automated future and artisans, many scholars have noted the rise in artisanal products in the present. Whether empowered by digital fabrication, or reliant on strictly traditional forms, meaningful, enjoyable labor is still a hallmark of artisanal work. Sennett (2008) notes that the concept of craftsmanship--doing a job well for its own sake-can be found as a fundamental human impulse throughout history. Ocejo (2017) shows that older, disparaged professions such as butcher have now been reborn by applying new technologies or "cultural repertoires", creating upscale versions that are revitalizing urban centers. Luckman (2015) finds that many features defined in the labor literature as "good work"-autonomy; interest and involvement; self-esteem; sociality; etc.--are associated with the rising number of these crafting professions. In their article "Investigating the value chain of modern artisanal innovation" Rao et al (2016) show how artisanal forms can flourish in a wide variety of technological scenarios, ranging from enabling hand-made sales by digital platforms (e.g. Etsy) 
to small scale automated production (e.g. Sole, which 3D prints shoes specific to each customer).

In addition to addressing the problem of job alienation, artisanal economies also hold promise for reducing ecological alienation; that is, for environmental sustainability. In many cases artisans are making a deliberate attempt to be more environmentally sustainable, using "green" supply chains and techniques, which can also empower their branding (Marsden and Smith 2005; Cimatti et al 2017). However, the sustainability dimension need not be artificially imposed. For example, Haro-Zea et al (2018) show that the burgeoning market for handicrafts in Chiapas, Mexico has been strongly tied to more sustainable sources of plant and mineral feedstock, simply by following traditional methods and sources. Carr and Gibson (2016) note a wide variety of sustainability gains from the artisanal economy, ranging from repair and reuse to the choice of supply chain materials.

The two features of the artisanal economy described above--as a solution to job alienation, and as a solution to environmental degradation--both play a role in the third feature, which is reducing social alienation. This aspect often emerges in artisanal attempts to address overconsumption. For example, Rüthschilling (2019) outlines the clothing collectives in Brazil that arose in response to the growing fashion industry: their aim is "to make fashion serve people's lives, bearing in mind that there are already too many clothes in the world". The solutions range from a textile maker space where lay citizens can create their own, to fabric recycling, to the incorporation of traditional textiles that have always made use of natural plant fibers. In their anthology of case studies of "ethical consumption" ranging from foods to furniture, Lewis and Potter (2011) note that "a greater use of localized craft designs, to produce higher-quality, better-made, longer-lasting goods with greater sensory-aesthetic qualities, would encourage the kind of small-scale, artisanal and sustainable forms of consumption required to support more ethical and aesthetic ways of life."

In sum: the potential advantages of moving to an artisanal economy include decreasing job alienation; increasing environmental sustainability, and replacing the damaging, commodityobsessed marketing society, geared towards over-consumption, with a more meaningful and intrinsically motivated network of localized producers and thoughtful consumption practices.

\subsection{Empowering the artisanal economy with automation technologies: addressing poverty and underrepresentation}

The work context of our research is in artisanal enterprises, broadly defined to include crafting physical artifacts (adornment, apparel, household goods, musical instruments, equipment, furniture, etc.); growing organisms (plants, fish, fungi, etc.); and other activities in which the "craftsmanship" concept of high quality, human-directed design, performance, or production applies. In some cases these participants craft as a "side job"; in other cases, they are small businesses (defined in the US as less than 500 employees).

Much of the literature on artisanal economies splits into two domains. Descriptions of strictly traditional forms often warn against the trap of "working poor" for handcrafted products (e.g. Scrase, 2003). In contrast, descriptions of artisans utilizing computational technologies, such as 3D printers or sophisticated, creative use of information systems ${ }^{2}$ often stress the relatively high

\footnotetext{
${ }^{2}$ For example, UX designers often see themselves as artisans, with creative skills and visions that are capable of producing unique, one-of-a-kind GUIs, websites and platforms. The fact that we now see UX
} 
socioeconomic status of these entrepreneurs, and lack of underrepresented ethnic groups (Kneese and Rosenblat 2014). Tanenbaum (2014) notes that "bike culture, local food culture, and artisanal culture attempt to connect hipsters to the neighborhoods they're accused of gentrifying". In other words, within the artisanal world, there is a gap between low-income, low tech; and high-income, high tech.

Thus, while we envision an artisanal economy empowered by automation such that it can encompass society in every socioeconomic class, we have made a special effort to start with lower income communities and underrepresented communities. If technology can empower an artisanal economy for these underserved groups, it can (arguably) do so for any. Conversely, if we leave these groups out, we are making the same "trickle down" arguments that have plagued technological optimism in the past. Finally, we note that these blue-collar groups are the most vulnerable to automation job loss.

The following section is divided into three parts. The first examines automation for artisanal economies at the micro-economic scale: as a worker in this process, how are tasks allocated among humans, machines, and hybrid collaborations of the two, such that we avoid labor value alienation? The second examines the meso-economic scale: how do we arrange relations with consumers and local institutions to decrease the problems of social and ecological alienation? The third section examines the macro-economic scale: how can a mechanism such as commons-based peer production (Bauwens et al. 2019) scale the artisanal economy from "local charm" to global significance, and what might the role of automation technologies play in maintaining egalitarian and sustainable relationships throughout that evolution?

\section{The micro-economic scale for artisanal automation}

\subsection{Preliminary experiments: from heritage algorithms to artisan-machine hybridity}

The alternative to mass production is often phrased as "design globally, manufacture locally" (Kostakis et al 2015) or "global bits, local atoms" (Gershenfeld et al 2017). Such frameworks are helpful in conveying the idea that it is more environmentally sustainable to manufacture locally than to ship items around the world. But it fails to capture the sense that there are locally specific algorithms. If a French designer is sending his digital file to be 3D printed in Senegal, where it is locally sold, with some profit share back to France, the system sounds suspiciously neocolonial; perhaps more environmental but still positioning Europe as the knowledge base and developing nations as market and materials source. Artisans, especially those operating in a cultural tradition, should be positioned as knowledge experts, not merely a cog in the wheel of sustainability.

Just as local gardeners can help to sustain biodiversity with heritage crops, we have found that local artisans can help to sustain cultural diversity with "heritage algorithms" (Bennett 2016). These are the underlying formal patterns of cultural artifacts. Examples include iteration in Navajo weaving, fractals in African American cornrows, nonlinear curves in urban graffiti, reflection symmetry in Latinx leather tooling, hexagonal tiling in Appalachian quilting, and so on.

designers complaining about the "McDonaldization" of their work (Kiess 2019) suggests they too are on a path similar to the fate befalling other artisans; hopefully similar solutions could be applied to their case. 
If I simply use a 3D scanner to copy an artisanal form, I have separated it from the making process and tradition. By collaborating with artisans to understand how their indigenous knowledge and practices are embedded in these patterns, heritage algorithms become a bridge between traditional and digital worlds. Thus we use the term "micro-economic scale" here not in terms of supply and demand, but rather to specify the scale of production typical of artisanal labor, particularly in how these heritage algorithms are communicated, modified, and physically $r^{3}$ endered.

Three sets of experiments were conducted on hybrids of traditional and automated fabrication at the micro-economic scale, each focused on a different cultural group: African American, Native American, and Ghanaian (located in west Africa). In each case we began by developing simulation tools based on the corresponding heritage algorithms. The initial phrase of the research was focused on virtual designs for STEM [Expand] education. Culturally Situated Design Tools (CSDTs), an open source archive of heritage algorithms (including both cultural background materials and simulation tools) was created with NSF funding for this purpose. In figure 1 at left we see African American high school students in a cosmetology program, learning to code with CSDTs and creating 2D braiding patterns. Using baseline measures and controlled studies, we were able to show statistically significant improvement for underrepresented students using these CSDTs in math, computing, and other educational contexts (Eglash et al 2006; Eglash and Bennett 2009, Eglash et al 2011; Babbitt et al 2015; Drazan et al 2017).

We developed the CSDT simulations through a respectful collaborative design process that begins in interviews with elders, artisans and other cultural representatives. The enthusiasm for having youth continue traditions in new media was striking. Some elders, who feared that their knowledge in Navajo weaving or Anishinaabe woodcraft was vanishing, were strong advocates for this synthesis between tradition and innovation. Several adults embraced the idea of deeper involvement. Thus began the second phase of the research, in which these simulations were physically rendered to bring value back to the adult artisanal economy.

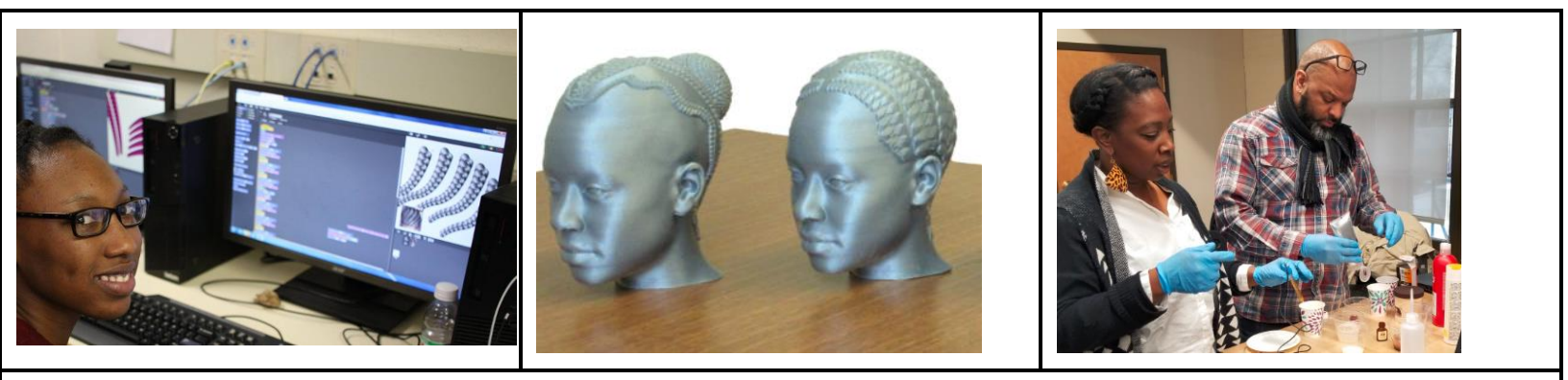

Figure 1: From heritage algorithms to 3D prints and new $\mathrm{pH}$ balanced hair products.

In figure 1 we see how the high school students' 2D braiding designs have been mapped as textures to 3D mannequin heads, which went to local hair salons. Adult cosmetologists at the 
salons asked to be more involved: they pointed to the importance of alternative care products made from organic sources. The next image in figure 1 shows these adults learning the use of $\mathrm{pH}$ meters with Arduino microprocessors. Their surveys indicated an increase in STEM perceptions and confidence. Bringing the adult work back into high schools launched a new initiative combining CS and chemistry with critique of the cosmetics industry; one youth has already started selling her organic products. Thus the value is maintained in unalienated form, and circulated rather than extracted.

Similar success emerged in other intergenerational collaborations. Our work with Anishinaabe (Great Lakes Indigenous) students facilitated their translation from the Indigenous knowledge of arc-based structures such as canoe ribs to creative simulations, carried out in the context of dialogs with adult traditional crafters, modern Ojibwe architects and other Native community members who were enthusiastic about hybrid fusions between Indigenous and computational worlds. Our study showed statistically significant increases in STEM career interest (Eglash et al. forthcoming). However, we noticed a distinct difference from African American participants: rather than render with 3D printers, Native youth preferred to physically render their creative virtual designs with a hand-crafting method, in which paper printouts of the virtual design is taped to wood as a template (Figure 2). Several suggested applications of their arc-based designs to greenhouses, aquaponics, and similar structures for growing food. Since Native Americans have the highest diabetes rate of any US ethnic group, this trajectory has been a new direction of investigation, as explained in section IV.2 below

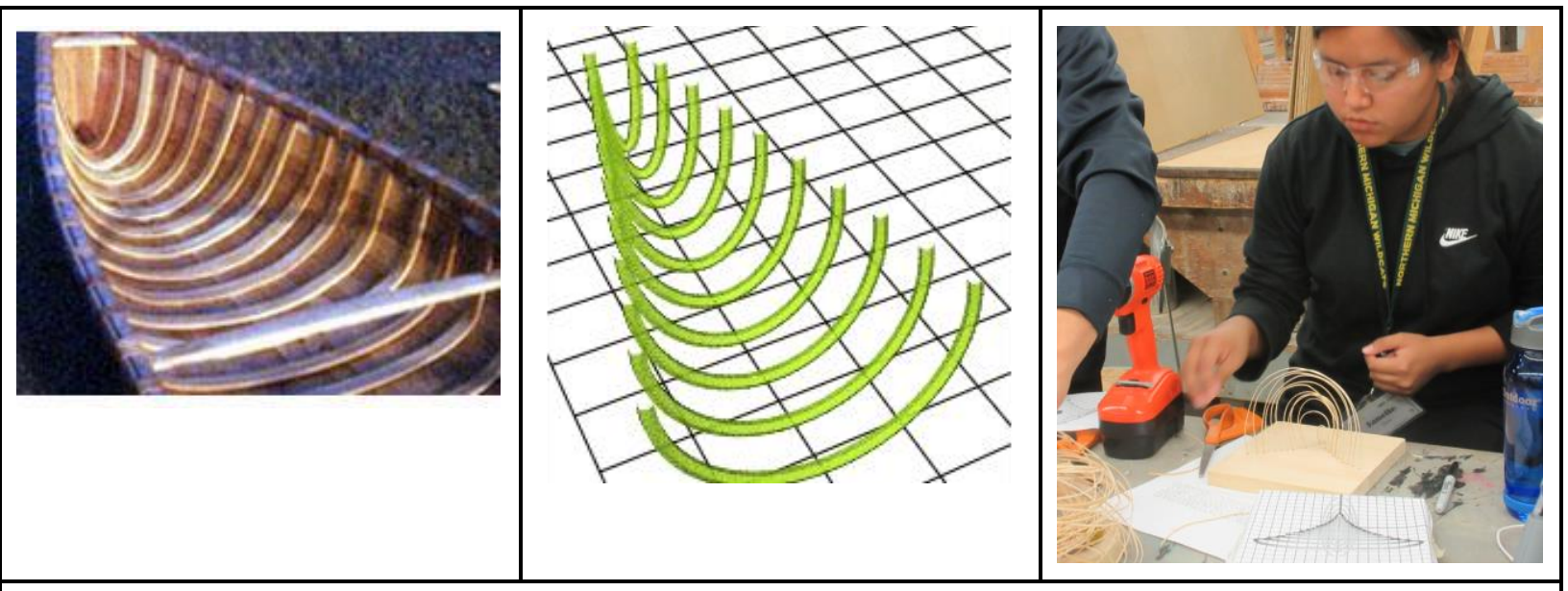

Figure 2: Indigenous arcs, to student-created simulation, to hybrid virtual-physical fabrication

A third option arose in our collaboration with a Ghanaian batik (wax print) collective, who had a growing pile of discarded latex sponge stamps. Responding to their request to reduce nonbiodegradable waste, we grew mushroom-based "mycofoam" in 3D printed molds, using virtual designs made by Ghanaian participants. Since CSDTs use a simple blocks-based visual 


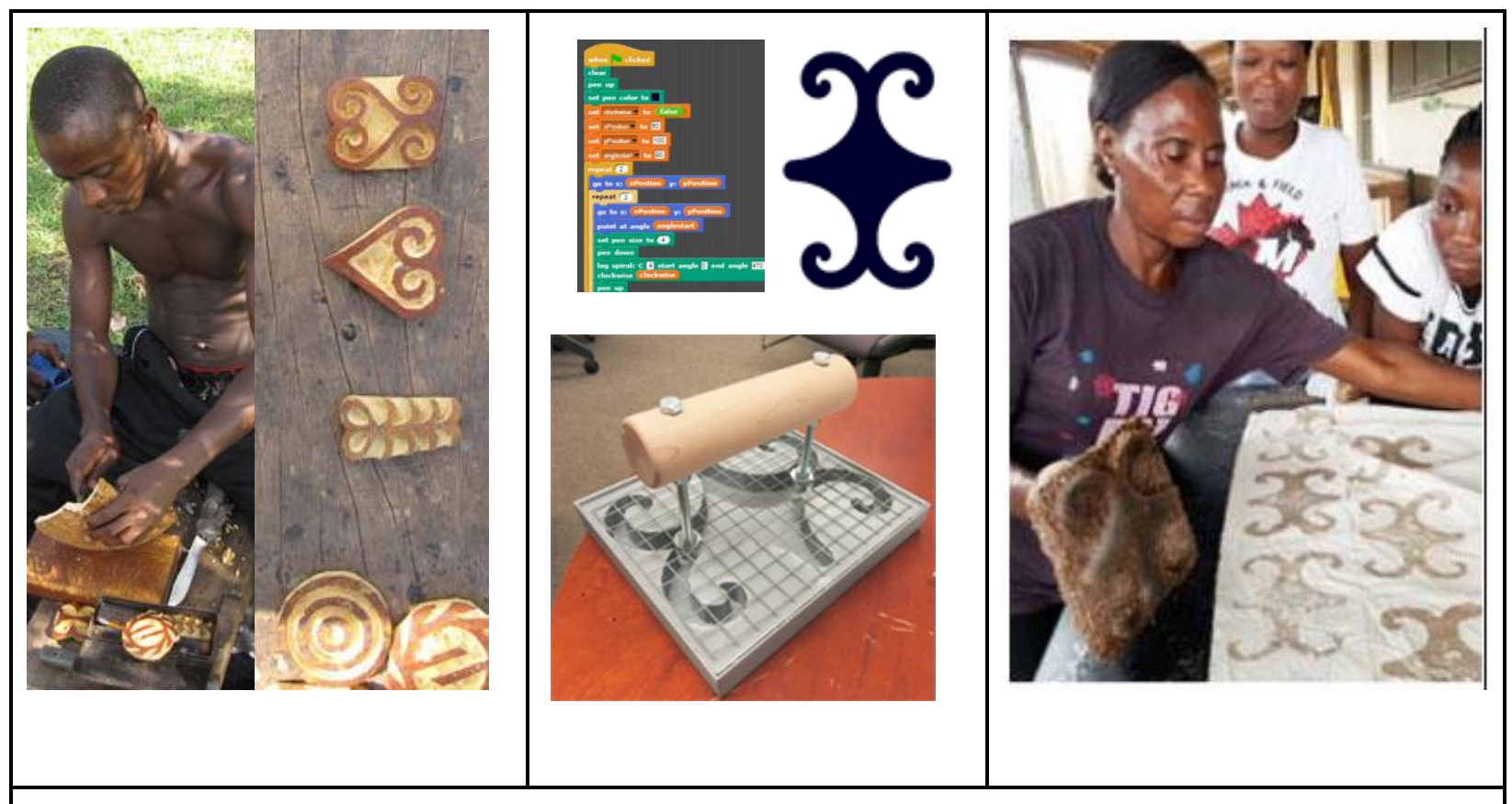

Figure 3: From traditional adinkra stamps, to simulation, to mycofoam mold, to batik cloth

programming interface, this created an opportunity for "upskilling". In a related controlled study, we found that Ghanaian learners more readily gained computational skills using CSDTs related to their traditional practice than in typical math and computing lessons (Babbitt et al 2015).

\subsection{Lessons learned at the micro-economic scale: hybrid diversity; upskilling; economic networks}

From these initial experiments, we have developed some provisional analysis. Keeping in mind that they are more hints at future research directions than definitive conclusions, they fall into three areas:

a. Hybrid diversity, not universality: In a well-cited paper on human-robot task allocation, Gombolay et al. (2015) conclude that "people preferred to cede their control authority to the robot." That may well be a universal for mass production assembly. But in the artisanal context, we find a great deal of variation: Native artisans preferred to have 3D virtual designs handassembled; emphasizing a relation to traditions suppressed by colonialism, and now undergoing revitalization (Corntassel 2012). African American artisans had 2D designs rendered by a fully automated 3D printer (Lachney 2017); reflecting sensibilities from Afrofuturism and related black urban repertoires. Ghanaian artisans combined computational printing with biodegradable mushroom foam; reflecting a traditional partnership with non-human agencies in nature. In contrast to Gombolay's study, this strategic diversity suggests that what is needed is not a single universal optimum, but rather a vetted "cookbook" in which artisans 
can choose from a wide variety of recipes for human-machine-nature hybrids, selecting those which best suit the traditions and context at any particular situation.

b. Upskilling, not deskilling: the general trend for human-machine interaction is toward voice commands, automation "at the touch of a button", and other ways to make human intervention as simple as possible. But this approach fails to appreciate the long-term trend towards "deskilling" in labor, which was deployed historically to disrupt shop floor control by machinists and others (Nobel 1979). To reverse that trend, the interface needs to find the "sweet spot" between ease of use and skills development. Future directions for this aspect of the project include the development of the CSDT website as an open-source, open-access research platform in which various functions within scripts can be seamlessly assigned to machine intelligence or human control as users and researchers see fit.

c. Networks, not pipelines: the "Fordist production" system of vertical corporations has given way to more flexible and networked modes of production, and workforce education is slowly responding. Our intergenerational collaborations between youth in vocational programs and adult artisans provide a potentially empowering model for "networked STEM" in which a new generation can embrace technology innovation without giving up a cultural identity, and adults can be more motivated to receive technological innovation that comes with an apprentice who might carry on the tradition in new ways. But just as important, our preliminary research shows a strong potential for the development of horizontal networks between local growers, fabricators, designers, educators, and others. Thus a third research area will be constituted by the development of automation technologies and accompanying human-machine collaborations to facilitate scaling up these networks into production ecosystems that can replace consumption-obsessed contemporary mass industry with unalienated value circulation.

\section{The meso-economic scale}

\subsection{Framing the challenges for artisanal economy value chains}

Above we use the phrase "micro-economic scale" to specify details of production labor tasks, sociocultural relationships to fabrication methods, and other features inside the site of production. In this section, we discuss the meso-economic scale: phenomena the interface between the enterprise and its externalities. Porter (1985) introduced the term "value chain" to describe this combination of resource inputs and consumption outputs; his goal was showing how to maximize value gains at minimum cost. For mass production economies, this value chain efficiency is often maximized by the destructive practice of externalizing costs.

To fully understand cost externalization from a generative perspective, it is helpful to recall physicist Erwin Schrödinger's 1944 book What is Life?, where he coined to term "negentropy" ("negative entropy"). By that he means living systems are fundamentally self-generating: biomolecules use autocatalysis; organisms use autopoesis; ecosystems use sympoiesis. By taking in energy, they self-produce and even self-heal. Thus a factory can externalize costs to nature: dumping toxins rather than bear the cost of filters; sengigding hot water into a stream 
rather than bear the cost of the cooling tower; and so on. Essentially it is extracting ecological value from nature's ability to self-heal. In the same way, workers will self-heal: we drive home exhausted, and drive to work replenished. Thus the factory can externalize costs to workers: by forcing them to pay for health care, child care, toxins, stress, boredom and so on the company is essentially extracting value from labor. In the third category, social value, manufacturing companies can externalize costs to cities when they bear the cost of infrastructure; media companies can externalize costs to families when their game-addicted children cannot function in school; and so on.

In each case, the resource can typically regenerate-- nature breaks down toxins; workers heal; society repairs--but essentially that means they are generating the value that is taken for profit. In other words, standard value chain efficiency is based on the goal of positioning the entity which generates value (people, plants, societies) as a point of extraction, with as little value as possible returned. In contrast, we can define artisanal economic efficiency as the opposite goal: minimizing value extraction; while maximizing its circulation in unalienated returns.

In the case of ecological value, mass production techniques in agriculture have been linked to soil depletion; pesticide "treadmills" (as pests evolve immunity); decline of the natural soil ecosystem; loss of biodiversity due to monocropping (which further exacerbates pest susceptibility); and other problems (Altieri 2009). In contrast, composting waste back into soil, multicropping (to allow the mutual support between nitrogen-fixating plants, insect-repelling plants, moisture conserving plants, etc.) and other networked flows creates a biodiverse and sustainable set of practices termed "agroecology" (Wojtkowski 2006). For example, in China's Pearl River delta mulberry tree leaves are fed to silkworms, which produce silk. The silkworm pupae go into fishponds to feed the fish, and fish waste and decayed matter in the pond mud is used as fertilizer for the trees. This 2,500 year old value cycle creates greater biodiversity and economic gains than conventional agriculture (Liu et al 2018). Agroecology essentially circulates ecological value in unalienated forms.

Similarly, when an artisan has a value chain that includes other artisans (under conditions in which they are all doing the work they love), then labor value is circulating in unalienated form. For example, as salaried jobs are lost to the "gig economy", a rise in worker cooperatives and other forms of "solidarity economy" have taken place (Cobble 2016; Johnston and LandKazlauskas 2018). Peer-to-peer exchanges of goods and services are increasingly common in these systems (Kuhn and Galloway 2015; Esim and Katajamaki 2017). Research suggests that the least alienation happens when this circulation occurs through a commons; hence the term "commons-based peer production" (Bauwens and Pantazis 2018). The artisanal product need not be low-tech; indeed open source coders who volunteer time on a project often describe themselves in exactly these terms: they are doing meaningful work, taking pride in crafting, and enjoying the circulation of this value through a "commons" (repository) without the alienation typical of work-for-hire (Coleman 2012; Ramsay 2015). While barriers to inclusion do exist in such contexts (Lewis 2015, Fox et al 2015) so too do platforms for inclusion (Lindtner et al 2016; Savic and Wuschitz 2018). 
We can measure the circulation of unalienated ecological value in metrics such as nutrient cycles or biodiversity (e.g. Liu et al 2018), and we can measure the circulation of unalienated labor value in metrics for peer-to-peer contributions through a commons (e.g. Callahan et al 2016). The circulation of social value is more elusive: solidarity, trust, conviviality, and similar "expressive" phenomena are difficult to measure except by proxy. Elinor Ostrom's famous studies (winning the Nobel Memorial Prize in Economics) shows that collaborative social capital is crucial to preventing a "tragedy of the commons" in traditional societies where lakes, grazing areas or other limited resources are voluntarily managed as public goods (Ostrom and Ahn 2009). Such examples are valuable reminders that authentic unalienated social value, circulated through and supportive of a peer-produced commons, is not only possible but a common feature of the Indigenous life that characterized humanity for much of its history.

In the contemporary context, however, nearly every online platform has tapped into social value as a resource: likes, shares, reviews, trust recommendations, and user contributions in every form imaginable. In some cases this is genuinely commons-based peer production, but in other cases the communality is a pernicious disguise. Just as labor value is extracted from workers in mass production, social value is extracted from consumers in these online platforms: ads, spyware, deceptively guided purchases, consumption-driving formations of taste, style, and opinion; an entire "attention economy" (Lanham 2006). Attempts to re-establish the kinds of traditional unalienated social value documented by Ostrom in these contemporary systems have led to varieties of "ethical consumption". Grauel (2016) notes that while these exist in a variety of explicit forms (Fair Trade, green consumers, vegans, freegans, and so on) they are still framed as presentations of the self since the producers are anonymous "others" in distant places.

\subsection{Preliminary research on automation and artisans at the meso-economic scale}

Two sets of experiments were conducted on networking artisanal value chains at the mesoeconomic scale. The first occurred over 2010-2015 in summer workshops in Kumasi, Ghana. One area of research concerned the use of condoms to prevent HIV transmission. Our interviews indicated that embarrassment at the point of purchase was a significant barrier to condom use. Working with Creativity Group, a local makerspace, we developed an open source, DIY (Do It Yourself) condom vending machine, with the intention of increasing privacy while promoting local manufacturing and ownership. The prototype was very successful: even a year later, the operator reported that she still had to refill the machine every morning, and described the success with the phrase "the machine doesn't judge you". Plans for scaling up the system included a smart machine that would text the owner when refills would be needed. Since cell phones are common even in low-income communities, this form of automation was not about replacing humans (the job of "vending machine checker" does not exist there). Rather the plan was introduced with the goal of allowing low-income owners to operate multiple machines at different locations.

One criticism was that the bare metal surface was aesthetically unattractive. Contacting the Adinkra artisans (figure 3 above), they supplied a cloth "skin" (figure 4). Although this was 


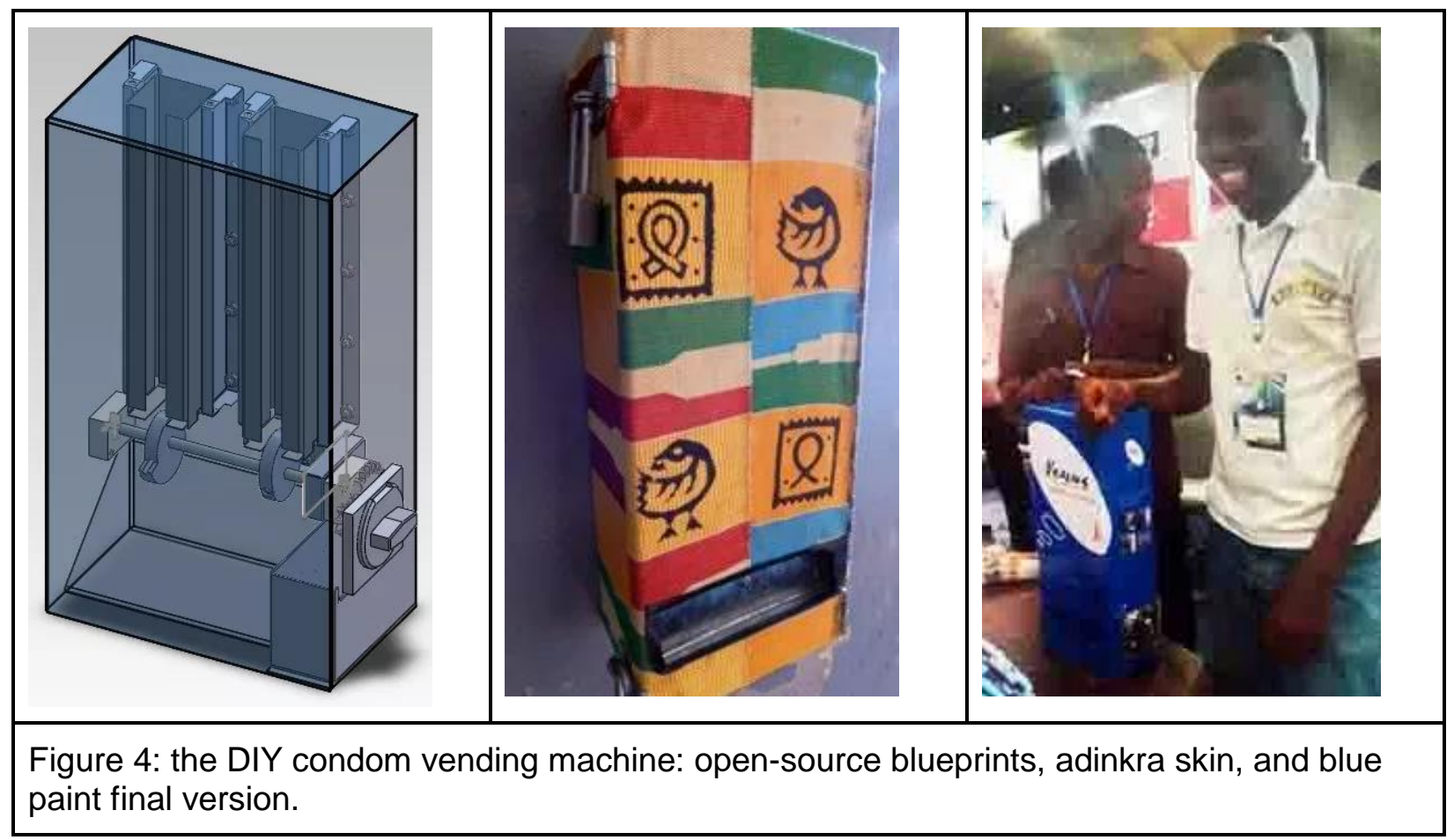

later rejected by the makerspace group (in favor of imported blue paint, and rebranded "Venus"), it indicates an important potential.

The Adinkra artisans make their own ink from boiling sustainably harvested tree bark, and they report that those forests are protected from deforestation due to this value (Eglash 2016). We are currently conducting experiments using solar heat to replace the wood fire currently used for bark ink (including automated process sensors and effectors). If that traditional system can be scaled, with its sustainability intact, then the more traditional ink produced, the more forest potentially under their protection. Applications for this sustainable dye to artisanal fabrication (as in the condom vending machine) is essentially networking between unalienated ecosystem value and unalienated artisanal labor; a crucial goal for the meso-economic scale. Below we will outline the potential for automation technologies to enhance this possibility.

The second experiment occurred in January 2019 in the U.S., where a public library community space in southeast Michigan hosted our workshop that brought together African American cosmetologists, urban agriculture staff, local educators, and other interested citizens. We briefly reviewed the prior research described in section III.1 above, and suggested that some of the plants grown by urban gardens could be used by cosmetologists to make $\mathrm{pH}$ balanced care products, forming at least one possible value chain. We also noted that the $\mathrm{pH}$ sensing devices, practices and techniques might be shared locally in an open source commons. There was then a hands-on training with Arduinos and pH sensors. Finally, we asked each group to create a $\mathrm{pH}$ display that reflected something about its use. Figure 5 shows the results. Because we encouraged creative adaptation, each display reflected the priorities of the group creating it. The 


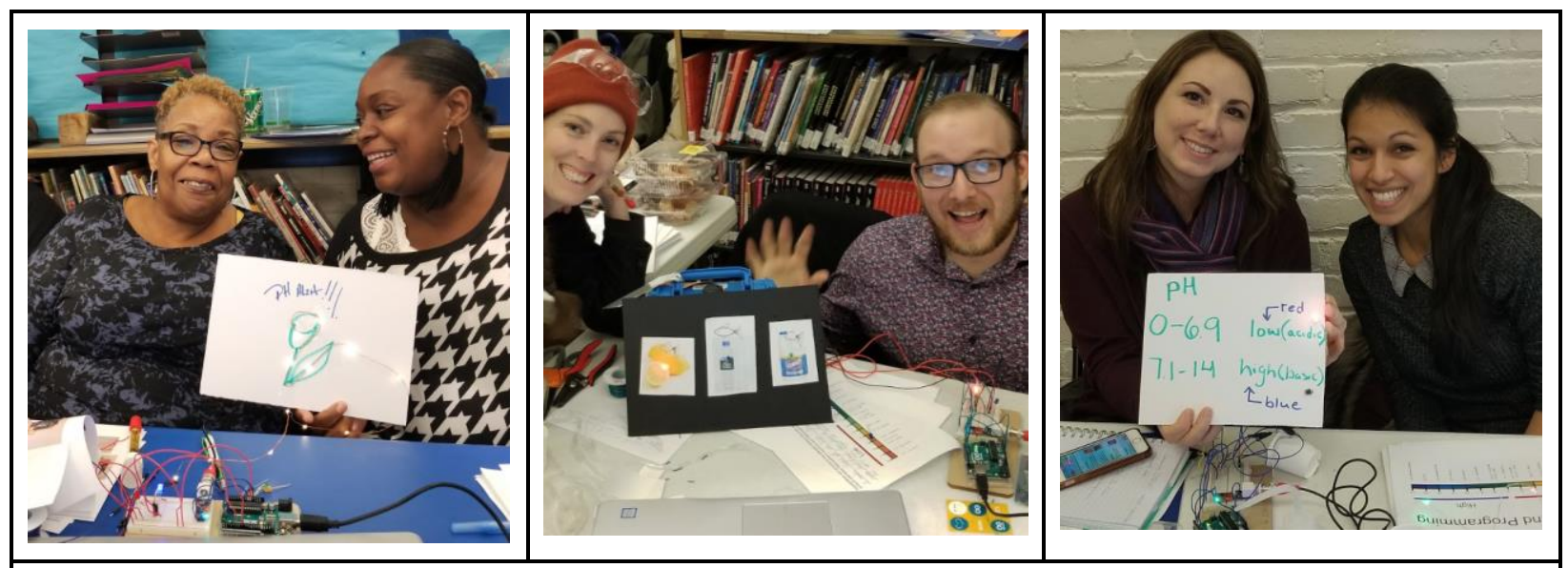

Figure 5: customization of automated sensing by different community groups

cosmetologists' alarm focused on imagery involving plants that would be used for hair care products. The urban agriculture group modified the circuit itself. The code we trained them with only had a single threshold, since cosmetologists were only concerned with hair product that were too alkaline. The urban agriculture group was building an aquaponics (fish plus plants) tank, so they added a middle range indicator, which they noted would be crucial for monitoring (and eventually automating) $\mathrm{pH}$ balance for fish. And the librarian/teacher pair created designs to maximize accuracy and communication of information. The network has continued since then. The library now hosts an aquaponics tank, which features plants selected by both growers and cosmetologists. A workshop for connecting sensors to mechanisms such as an automatic fish feeder is planned for summer.

\subsection{Automation for enhancing meso-scale networks in the artisanal economy}

The two experiments in networking described above--Adinkra/condom machines in Ghana and cosmetologists/urban growers in Michigan--are at very preliminary stages, but they illustrate two important principles regarding automation. First, certain negative aspects of automation typically tied to alienation are mitigated by the strategic and contextual diversity in artisanal networks. In the case of Ghana, the barrier to condom purchase was not lack of human connection. It was the opposite, feelings of too much connection; of community surveillance. Automation (the vending machine) provided a much-needed shield of anonymity; while the localized production and ownership prevented value alienation. Similarly, while the sensor displays created by each group reflected their own priorities, the librarian group made their version as generic as possible. This was their strategic choice: universalism was a personal commitment for the librarians, just as fish health and hair product quality were for growers and cosmetologists. In both Ghana and Michigan, the effects of automation that are problematic in mass production economies--generic, faceless machines; universalized information forms--could be strategically deployed in artisanal exchanges that kept value unalienated. 
Second, the automation elements that could best support the emergence of meso-scale artisanal economy networks appeared to be very different from visions of mass production automation, where the emphasis is on replacing humans in jobs that already exist (assembly robots or automated vehicles). The artisanal automation elements tended towards jobs that do not yet exist, and much of the technology was more along the lines of "ubiquitous computing" sensors (eg pH across different activities; smart vending machines that text when empty), or effectors doing small scale versions of current automation in process engineering (e.g. solar ink production in Ghana required automatic shut-off circuits or it would over-cook). While these are very small scale experiments, one can imagine how Al could be applied to scale: coordinating sustainable ink production over hundreds of artisanal shops so that bark harvest locations are spread out to maintain sustainability; optimized for bark quality, adjusted for weather, etc.

Keeping both principles in mind--the need to allow "generic" automation effects when contextually appropriate, and the advantages to ubiquitous and process computing in support of diverse, locally specific production forms--we can envision a broad number of automation technologies for scaling up, establishing or enhancing meso-economic networks. Tech start-ups in the developing world show strong benefits from networked relationships, but that is in tension with fitting to a profit-oriented, extractive economy (World Bank 2018). In the experiments above we "manually" provided pairing to keep value flow in unalienated form; and that required some insight (e.g. to realize that plant products created by urban growers could be linked to the alternative hair products of interest to cosmetologists for example). Replacement of that manual pairing with automation (without requiring a level of Al that may not be available in the near future) could be accomplished by creating a database of feedstocks, services, products, and other elements of the artisanal value chain. The ability of Al to find the means of offering new linkages would have to be built from a training data set in which extensible instances are already established.

Current potential training data sets might be derived from various online foundations and archives for generative economies (although Natural Language Processing or some other means would be needed to deal with inconsistencies in formats and representations). The P2P Foundation has its origins in the "peer to peer production" digital labor framework of Benkler (2006) and Bauwens (2012), and was founded with the intention of facilitating an allencompassing physical and social alternative economy. Their "P2P directory" includes 385 "live" cases as of 2019; while these are not broken down by value chain elements the potential to do so exists. An associated site, commonstransition.org, is further distanced from dependence on earlier digital labor models and provides the Commons Transition Wiki as a repository with larger scale case studies and other potential sources for training data. Other sets of potential sources are those associated with MIT's FabLab initiative, including FabCity and the FabEconomy platforms (Gershenfeld et al 2017), and the LIVEWHAT project, which was conducted in France, Germany, Greece, Italy, Poland, Spain, Sweden, Switzerland and the UK, gathering data on 46,550 websites of "alternative action organizations" for grassroots economic and civic activity (Kousis et al 2018). 
While the above focus mainly on unalienated labor and expressive value, there are also more readily available databases focused on environmentally sustainable sourcing, although that remains a complex decision-making challenge (Thorlakson et al 2018). National Institute of Standards and Technology (NIST) for example hosts an online tool which quantifies life-cycle environmental and cost performance for 230 building products, each evaluated across 12 environmental-impact categories (and this is just one of several such databases). Automation in artisanal value chains need not be restricted to identifying providers. Visual pattern recognition, for example, might be used to empower currently inaccessible resources, such as picking out valuable pieces of lumber from waste wood, or selecting other elements in a waste stream. Similar Al applications at higher scales might utilize Geographic Information Systems (GIS) to incorporate weather, pest threats, road conditions, and other data to optimize natural resource utilization in concert with nature's' rhythms, rather than the mass production approach of mechanizing nature (McLain et al 2014). In addition to identification, using the automation technologies to organize resources in aggregate might empower artisans towards the creation of cooperatives, collective bargaining or other structures.

A similar area for investigation is in the battle against goods deceptively sold as handmade but actually mass produced (Tabuchi 2015). Al-enabled identification (e.g. unsupervised feature learning) could be used to authenticate an artisan's true handcraft. Similar approaches have been successfully used to recognize styles in painting (Gultepe et al 2018). Traditional academic workshops on art investigation, such as the Image Processing for Art Investigation conference (IP4AI) have historically focused on investigating western forgeries while dismissing the growing problem of artisanal forgeries, such as fake textiles. A publicly accessible ground truth dataset of artisanal artifacts, having both authentic and forged work, would allow the field of art investigation to approach the problem of forgery detection in artisanal work while also providing a new basis for socio-economic equity in how works of art are protected. If Al identification was applied in conjunction with a consumer app; for example enabling a video of that particular fabric as it was made, it could strengthen the personal connections that are the hallmark of authentic artisanal production.

In all of the above cases of automation at the meso-scale, the design must be founded on the principles of generative justice: "the universal right to generate unalienated value and directly participate in its benefits; the rights of value generators to create their own conditions of production; and the rights of communities of value generation to nurture self-sustaining paths for its circulation" (Eglash 2015). As our initial experiments caution, such grass-roots democratization of automation technologies can lead to what experts (even artificial experts) regard as less optimal--choosing imported blue paint over local sustainable pigments for example--but for that reason artisanal automation must always be limited to an advisory role. We side with the optimists of democratic rule--from Condorcet and Jefferson to Emma Goldman and M.L. King--that the moral arc of the universe is best bent towards justice by pulling from the bottom, not pushing from the top.

\section{The macro-economic scale}


At the macro-economic scale, current mass production economies are driven by metrics, policies and infrastructures that were made specifically to support their perpetuation. For example, economist David Pilling (2014) refers to GDP as "an artefact of the age of mass production", noting that GDP for a nation that allowed pollution, infrastructure decay and social inequality in exchange for more product sales could give the illusion of wealth without its substance. Alternative metrics for an artisanal economy could be based on the ratio between alienated and unalienated value; rates of unalienated value flow; or simply metrics reflecting well being and flourishing of human and non-humans throughout its diverse environments.

To the extent that $\mathrm{Al}$ and other automation technologies are embedded in the meso-scale artisanal networks, and that appropriate anonymization is made possible by blockchain or other kinds of encryption, they could also be utilized as data sources for such metrics. A recent initiative using blockchain driven surveys to measure the well-being of apparel industry workers in factory settings (Węziak-Białowolska et al 2019, SHINE 2018), appeared to have findings consistent with the critique we have presented here. Job decision authority, which tends to be greatly diminished in mass production, had one of the strongest correlations with job satisfaction, second only to the factor of "trust, respect and recognition". At the meso scale, Papadaki and Kalogeraki (2018) gathered data from Greek organizations in the Solidarity economy--worker owned cooperatives, fair trade networks, solidarity-based credit organisations, alternative food networks, and other grassroots economic forms created during the Greek financial crisis. Of 500 organizations in the sample, over $50 \%$ utilized alternative value forms, such as swapping, bartering, and even locally invented currencies. Thomas and Samuel (2017) examine 76 open source product development projects, and show how new variables were needed to understand the ecosystem of value creation. Alternative metrics and methods of these sorts are needed if we expect data analysis to inform and guide a distributed, artisanal economy better than the current metrics, which have misguided mass economies.

The formation of policies that currently reflect the priorities of mass production economies can be illuminated by a look at exclusionary intellectual property regimes. For example, until 2013 US intellectual property law allowed naturally occurring genetic sequences to be patented, resulting in corporate "ownership" of the DNA coding for insulin, vitamin $\mathrm{B}_{12}$, and other forms that would otherwise be available to all as part of the commons of ecological value. Once opensourced through responsible forms of DIY bio, artisanal economies for genetic information are made possible. For example, an "open insulin" project has started to produce life-saving, patentfree medicine at a fraction of its cost in current retail (Gallegos, 2018). The kitchen-sized lab, whose modified yeast strains are open source (for anyone to propagate and use), is essentially artisanal genetic engineering.

One can similarly argue that just as the supreme court ruled natural DNA sequences a part of the commons of ecological value, Al should be understood as part of the commons of expressive value. Human intellect can potentially be emulated just as human DNA can be, and it is just as much the product of millions of years of evolution. Thomas Jefferson, who authored the line on "unalienable rights" in the declaration of independence, was also an opponent of patents, and essentially foreshadowed open source: "That ideas should freely spread from one 
to another over the globe, for the moral and mutual instruction of man... seems to have been peculiarly and benevolently designed by nature, when she made them, like fire, expansible over all space, without lessening their density in any point" (1813). ${ }^{4}$

While great strides have been made in the release of Al as open source frameworks, the means of translating the power of $\mathrm{Al}$ and associated robotic technologies to forms available to common people is, so far, barely developed. When Gutenberg created awareness of the printing press in 1455 it was with a Bible written in Latin, which common people could not read. The democratizing power of printing technology did not occur until 80 years later when the printings in English, French, and other common tongues began. Similarly, infrastructure for translating automation technologies into forms that can allow ordinary citizens to leverage grassroots economic and civic value generation is the next barrier to be surmounted.

The Commons Transition network writers (Kostakis et al 2015; Bauwens and Alekos 2018) have proposed one such infrastructure in the form of a "peer production license", which would require a contribution to the commons by for-profit companies. Just as the carbon tax is envisioned as a path towards low-carbon industry by redistributing a share of high-carbon profits, they envision a similar provisioning of capital in the transition to commons-based peer production. However, any form of enforcement (even a carbon tax) may be difficult in the current political climate. Platform cooperativism (Scholz and Schneider, 2016) is one potential alternative. Rather than Uber and Lyft's approach to minimizing returns to workers in a "gig economy" (Johnston and LandKazlauskas 2018), companies such as Green Taxi in Colorado are using a similar ride-hailing app to support a worker-owned cooperative. Scholz and Schneider document similar approaches in Fairbnb (worker-owned version of Airbnb); Stocksy (worker-owned version of ShutterStock); and so on.

In both cases (commons-based and platform cooperative) technological innovation is required if automation technologies are to be fully integrated, and these must also be supported by innovations in legal and social frameworks, as well as policy orientations. As Saner et al (2012) note, worker cooperatives are "conspicuously absent in trade and development discourse". Greater support has been gained in local government policy. For example, Berkeley California (like many cities) offers support for women and minority-owned businesses: this includes a revolving loan fund, preference for city contracts, and ongoing technical assistance. In February 2019 it became the first city to extended this support to help existing small businesses convert to worker cooperatives. One might imagine that in such contexts, capital funds for artisanal automation would garner far greater support than that for mass production automation.

Automation technologies which can support such sociotechnical infrastructures may substantially differ from those created specifically for mass production economies, which generally have the goal of replacing human workers. As Gutenberg's printing technology gradually shifted from the elite's Latin to the language of common people, supporting

\footnotetext{
${ }^{4}$ Jefferson's notorious failure to include race and gender in his formulations also parallels some dilemmas of today's makerspace and open source inclusion problem, where the rhetoric of "open to all" does not match the demographics of participants (Lewis 2015, Fox et al 2015).
} 
modifications in typeface, paper production, press mechanisms, publication distribution, and other innovations followed. The technology itself was changed in the effort to accommodate a less elite audience. And once more could read, a kind of co-evolution between communication and culture enabled similar shifts away from elite authority in religion (protestant reformation); science (popular books and demonstrations); and politics (no coincidence that American revolutionaries like Benjamin Franklin were so involved in printing and distribution). We have yet to see similar innovations democratizing automation technologies for use by common people, but we hope it is clear that we advocate for bottom-up co-evolution-not a grand design imposed from above--as a strategy to maintain control in the grassroots.

\section{Conclusion}

This paper has reviewed the potential role of automation in creating a future vision for what we refer to as an artisanal or "generative" economy: one in which labor value, ecological value, and expressive value remains in unalienated form, circulating through commons-based production rather than extracted for external exploitation. We outlined the destructive tendencies of current mass-production; and reported on initial experiments in which digital technologies were merged in a synthesis with African American, Native American, and African artisanal traditions, as well as with other community organizations.

At the micro-economic scale, our analysis contrasts with the view of a single optimum for human-machine task allocation that is implied elsewhere in the literature. Rather we find that participants preferred a diversity of hybrid forms; corresponding to the sociocultural and ecological diversity of the artisans and contexts, and that this diversity was fundamental to sustaining artisanal production as a more pleasurable, meaningful, and sustainable alternative to mass production. At the meso-economic scale, our initial experiments connecting makerspace fabricators, traditional artisans and natural resources in Ghana, and urban artisans and growers in Michigan, indicates that connecting the flow of unalienated value from labor, environment and expressive generation requires significant innovation if it is to develop as a self-sustaining economic network. Our research, however, indicates that the kinds of data mining, pattern recognition and related tasks required are well within the grasp of humanautomation symbiosis. Finally, at the macro-economic scale, we point towards worker-owned platforms and innovations in commons-based peer production as areas in which automation innovation and artisanal economic structures can co-evolve. But we caution that policy formulation, widely adopted metrics and other kinds of legal, political and civic infrastructure are needed to support such transformations. In sum: we hope this project will show how the powerful automation technologies such as Al can best serve social justice and sustainability not as a trickle--down of innovation from above, but as bottom-up empowerment starting from the grassroots.

\section{References}

Altieri, M. A. (2009). The Ecological Impacts of Large-Scale Agrofuel Monoculture Production Systems in the Americas. Bulletin of Science, Technology \& Society, 29(3), 236-244. 
Babbitt, William, Michael Lachney, Enoch Bulley, and Ron Eglash. "Adinkra Mathematics: A Study of Ethnocomputing in Ghana." Multidisciplinary Journal of Educational Research 5, no. 2 (June 15, 2015): 110-35.

Bauwens, Michel, \& Pantazis, Alekos. (2018). The ecosystem of commons-based peer production and its transformative dynamics. The Sociological Review, 66(2), 302-319. London, England: SAGE Publications.

Bunce, L., Amy Baird, A., and Jones, S. (2017) The student-as-consumer approach in higher education and its effects on academic performance, Studies in Higher Education, 42:11, 19581978,DOI: $10.1080 / 03075079.2015 .1127908$

Burawoy M. 2006. "Antinomian Marxist". In The Disobedient Generation: Social Theorists in the Sixties, ed. A Sica, S Turner, pp. 48-71. Chicago: Univ. Chicago Press.

Callahan, B. R., Hathaway, C., \& Krishnamoorthy, M. (2016). Quantitative Metrics for Generative Justice: Graphing the value of diversity. Teknokultura, 13(2), 567-586.

Carr, C., \& Gibson, C. (2016). Geographies of making: Rethinking materials and skills for volatile futures. Progress in Human Geography, 40(3), 297-315.

https://doi.org/10.1177/0309132515578775

Chancellor, Joseph, and Sonja Lyubomirsky. "Happiness and Thrift: When (Spending) Less Is (Hedonically) More.” Journal of Consumer Psychology 21, no. 2 (April 1, 2011): 131-38. https://doi.org/10.1016/j.jcps.2011.02.004.

Cimatti, B., Campana, G., \& Carluccio, L. (2017). Eco Design and Sustainable Manufacturing in Fashion: A Case Study in the Luxury Personal Accessories Industry. Procedia Manufacturing, 8, 393-400.

Cobble, D. S. (2016). Worker mutualism in an age of entrepreneurial capitalism. Labour \& Industry: a journal of the social and economic relations of work, 26(3), 179-189.

Coccia, M. (2017). Global Negative Effects of the Technological Change on Human Health: The High Incidence of Cancers in the Anthropocene.

Coleman, E. Gabriella. Coding freedom: The ethics and aesthetics of hacking. Princeton University Press, 2012.

Corntassel, J. (2012). Re-envisioning resurgence: Indigenous pathways to decolonization and sustainable self-determination. Decolonization: indigeneity, education \& society, 1(1).

de Souza Machado, A. A. (2016). Coastal and marine pollution in the Anthropocene: Identifying contaminants and processes. Coastal pollution of aquatic systems, 17.

Diez, T., \& Posada, A. (2013, February). The fab and the smart city: the use of machines and technology for the city production by its citizens. In Proceedings of the 7th international conference on tangible, embedded and embodied interaction (pp. 447-454). ACM. 
Dirzo, R., Young, H. S., Galetti, M., Ceballos, G., Isaac, N. J., \& Collen, B. (2014). Defaunation in the Anthropocene. science, 345(6195), 401-406.

Drazan, J. F., Loya, A. K., Horne, B. D., \& Eglash, R. (2017). From Sports to Science: Using Basketball Analytics to Broaden the Appeal of Math and Science Among Youth. MIT Sloan Sports Analytics Conference 2017.

Eckert , S. Collaborative robot market set for phenomenal growth. Oct 11, 2016. Retrieved from https://www.rethinkrobotics.com/blog/collaborative-robot-market-growth/ January 1, 2019.

Eglash, R., Bennett, A., O'donnell, C., Jennings, S., \& Cintorino, M. (2006). Culturally situated design tools: Ethnocomputing from field site to classroom. American anthropologist, 108(2), 347-362.

Eglash, R and Bennett, A. (2009). Teaching with Hidden Capital: Agency in Children's Computational Explorations of Cornrow Hairstyles. Children, Youth and Environments pp. 5874, 19 (1) 2009.

Eglash, R., Krishnamoorthy, M., Sanchez, J., and Woodbridge, A. (2011). Fractal simulations of African design in pre-college computing education. ACM Transactions on Computing Education, v11 n3 Article 17 Oct 2011.

Eglash, R., Lachney, M., Babbitt, W., Bennett, A., Reinhardt, M., Davis. J. (forthr). Decolonizing Education with Anishinaabe Arcs: Generative STEM as a Path to Indigenous Futurity.

Eglash, R. (2016). Of marx and makers: An historical perspective on generative justice.

Teknokultura, 13(1), 245-269.

Esim, S., \& Katajamaki, W. (2017). Rediscovering worker cooperatives in a changing world. lusLabor, (1).

Fox, S., Ulgado, R. R., \& Rosner, D. (2015). Hacking culture, not devices: Access and recognition in feminist hackerspaces. In Proceedings of the 18th ACM Conference on Computer Supported Cooperative Work \& Social Computing (pp. 56-68). CSCW '15. New York, NY: Association for Computing Machinery. doi: 10.1145/2675133.2675223

Gallegos, J. E., Boyer, C., Pauwels, E., Kaplan, W. A., \& Peccoud, J. (2018). The Open Insulin Project: A Case Study for 'Biohacked'Medicines. Trends in biotechnology.

Gershenfeld, N., Gershenfeld, A., \& Cutcher-Gershenfeld, J. (2017). Designing reality: How to survive and thrive in the third digital revolution. Basic Books.

Gombolay, M. C., Gutierrez, R. A., Clarke, S. G., Sturla, G. F., \& Shah, J. A. (2015). Decisionmaking authority, team efficiency and human worker satisfaction in mixed human-robot teams. Autonomous Robots, 39(3), 293-312.

Grauel, J. (2016). Being authentic or being responsible? Food consumption, morality and the presentation of self. Journal of Consumer Culture, 16(3), 852-869. 
Gultepe, E., Conturo, T. E., \& Makrehchi, M. (2018). Predicting and grouping digitized paintings by style using unsupervised feature learning. Journal of Cultural Heritage, 31, 13-23.

Haro-Zea, K., Haro-Zea, Y., Roblero-Mazariegos, G., \& Sánchez, S. (2018, January). Chiapaneca Handicraft as a Driver of Sustainable Local Development. In Global Conference on Business and Finance Proceedings (Vol. 13, No. 1, pp. 89-97).

Jambeck, Jenna R., Roland Geyer, Chris Wilcox, Theodore R. Siegler, Miriam Perryman, Anthony Andrady, Ramani Narayan, and Kara Lavender Law. "Plastic Waste Inputs from Land into the Ocean." Science 347, no. 6223 (February 13, 2015): 768-71. https://doi.org/10.1126/science.1260352.

Johnston, H., \& Land-Kazlauskas, C. (2018). Organizing on-demand: Representation, voice, and collective bargaining in the gig economy. Conditions of work and employment series, 94 .

Kannan, K. (1991). Fundamentals of environmental pollution. S. Chand \& Company.

Karasek, R. (1979). Job Demands, Job Decision Latitude, and Mental Strain: Implications for Job Redesign. Administrative Science Quarterly, 24(2), 285-308. doi:10.2307/2392498

Karasek, R., Baker, D., Marxer, F., Ahlbom, A., \& Theorell, T. (1981). Job decision latitude, job demands, and cardiovascular disease: a prospective study of Swedish men. American journal of public health, 71(7), 694-705.

Kiess, C. "The McDonaldization of UX". Available at https://uxdesign.cc/the-mcdonaldization-ofux-705438fea958 (accessed April 30, 2019).

Kneese, T., \& Rosenblat, A. (2014). Technologically Mediated Artisanal Production. Open Society Foundations' Future of Work Commissioned Research Papers.

Kostakis, V., Niaros, V., Dafermos, G., \& Bauwens, M. (2015). Design global, manufacture local: Exploring the contours of an emerging productive model. Futures, 73, 126-135.

Kousis, M., Kalogeraki, S., \& Cristancho, C. (2018). Alternative Action Organizations During Hard Economic Times: A Comparative European Perspective. American Behavioral Scientist, 62(6), 733-738. https://doi.org/10.1177/0002764218768845

Kuhn, K. M., \& Galloway, T. L. (2015, May). With a little help from my competitors: peer networking among artisan entrepreneurs. Entrepreneurship: Theory and Practice, 39(3), 571

Lachney, M. (2017). Computational communities: African-American cultural capital in computer science education. Computer Science Education, 27(3-4), 175-196.

Lachney, M., Babbitt, W., Bennett, A., Eglash, R. (Forthcoming). Generative Computing: African-American Cosmetology as a Link Between Computing Education and Community Wealth. Interactive Learning Environments.

Lanham, R. A. (2006). The economics of attention: Style and substance in the age of information. University of Chicago Press. 
Lewis, J. (2015). Barriers to women's involvement in hackspaces and makerspaces. Access as spaces. Available at: http://access-space. org/wp-content/uploads/2015/10/Barriers-to-womensinvolvement-in-hackspaces-and-makerspaces. pdf (accessed 10 May 2016).

Lewis, T., \& Potter, E. (2013). Ethical consumption: A critical introduction. Routledge.

Lindtner, S., Bardzell, S., \& Bardzell, J. (2016, May). Reconstituting the utopian vision of making: $\mathrm{HCl}$ after technosolutionism. In Proceedings of the $2016 \mathrm{CHI}$ Conference on Human Factors in Computing Systems (pp. 1390-1402). ACM.

Liu, S., Min, Q., Jiao, W., Liu, C., \& Yin, J. (2018). Integrated Emergy and Economic Evaluation of Huzhou Mulberry-Dyke and Fish-Pond Systems. Sustainability, 10(11), 3860.

Luckman, S. (2015). Craft and the creative economy. Springer.

Marsden, T., \& Smith, E. (2005). Ecological entrepreneurship: sustainable development in local communities through quality food production and local branding. Geoforum, 36(4), 440-451.

McLain, R. J., Hurley, P. T., Emery, M. R., \& Poe, M. R. (2014). Gathering "wild" food in the city: rethinking the role of foraging in urban ecosystem planning and management. Local Environment, 19(2), 220-240.

Michelsen, H., \& Bildt, C. (2003). Psychosocial conditions on and off the job and psychological ill health: depressive symptoms, impaired psychological wellbeing, heavy consumption of alcohol. Occupational and environmental medicine, 60(7), 489-496.

Morell, M. F., \& Espelt, R. (2018, August). How Much are Digital Platforms Based on Open Collaboration?: An analysis of technological and knowledge practices and their implications for the platform governance of a sample of 100 cases of collaborative digital platforms in Barcelona. In Proceedings of the 14th International Symposium on Open Collaboration (p. 26). ACM.

Morrison, P. D., Roberts, J. H., \& Midgley, D. F. (2004). The nature of lead users and measurement of leading edge status. Research policy, 33(2), 351-362.

Nadler, R. (2014). Neuroscience, Neuroethics, and Advertising. SLS Blogs, Feb 2, 2014.

Ocejo, R. E. (2017). Masters of Craft: Old Jobs in the New Urban Economy. Princeton University Press.

Ostrom, E., \& Ahn, T. K. (2009). The meaning of social capital and its link to collective action. Handbook of social capital: The troika of sociology, political science and economics, 17-35.

Papadaki, M., \& Kalogeraki, S. (2018). Exploring Social and Solidarity Economy (SSE) during the Greek Economic Crisis. Partecipazione e Conflitto, 11(1), 38-69.

Ramsay, M. (2015). Resisting Alienated Labour Through Hacking: The Case of Free and Open Source Software (Doctoral dissertation). 
Rüthschilling, E. A. (2019). Sunshine on a Cloudy Day. In A. Gwilt, A. Payne, and E. Rüthschilling, Global Perspectives on Sustainable Fashion, (pp. 2-12), New York: Bloomsbury.

Saner, R., Yiu L., Filadoro, M. (2012), "Cooperatives for inclusive growth”, CSEND Policy. Brief, n. 10. ISSN 2235 8048, Geneva.

Savic, S., \& Wuschitz, S. Feminist Hackerspace as a Place of Infrastructure Production. Ada issue 13, 2018.

Schrödinger, E. What is Life? Cambridge University Press, Cambridge, 1944.

Scrase, T. J. (2003). Precarious production: globalisation and artisan labour in the Third World. Third World Quarterly, 24(3), 449-461.

Sennett, R. (2008). The Craftsman. Yale University Press.

Scholz, T., \& Schneider, N. (Eds.). (2017). Ours to hack and to own: The rise of platform cooperativism, a new vision for the future of work and a fairer internet. OR books.

Story, M., \& French, S. (2004). Food Advertising and Marketing Directed at Children and Adolescents in the US. The international journal of behavioral nutrition and physical activity, 1(1), 3. doi:10.1186/1479-5868-1-3.

Tabuchi, H. (2015). Etsy's Success Gives Rise to Problems of Credibility and Scale. The New York Times (March 15).

Tanenbaum, Laura. (2014). "My Brooklyn, Not Yours.” Jacobin, 13. https://www.jacobinmag.com/2014/01/my-brooklyn-not-yours/

Thompson, D. (2015). A world without work. The Atlantic, 316(1), 50-61.

Thomas, L., \& Samuel, K. (2017). Characteristics of Open Source Business Models. In ISPIM Conference Proceedings(pp. 1-15). The International Society for Professional Innovation Management.

Thorlakson, T., de Zegher, J., \& Lambin, Eric (2018) Companies' contribution to sustainability through global supply chains. Proceedings of the National Academy of Sciences Feb 2018, 115 (9) 2072-2077; DOI: 10.1073/pnas.1716695115

Vallero, D. A. (2014). Fundamentals of air pollution. Academic press.

World Bank. 2018. Tech startup ecosystem in West Bank and Gaza : findings and recommendations (English). Washington, D.C. : World Bank Group.

http://documents.worldbank.org/curated/en/715581526049753145/Tech-startup-ecosystem-inWest-Bank-and-Gaza-findings-and-recommendations

Woo, J. \& Postolache, T. (2011). The impact of work environment on mood disorders and suicide: Evidence and implications. International Journal on Disability and Human Development, 7(2), pp. 185-200. 
Wojtkowski, Paul A. (2006) Introduction to Agroecology: Principles and Practices. Haworth Press, Binghamton, NY. 